\title{
The Role of Laws Within \\ the Governance of Volcanic Risks
}

\author{
R. J. Bretton, J. Gottsmann and R. Christie
}

\begin{abstract}
The governance of volcanic risks does not take place in a vacuum. In many cultures, volcanic risks are perceived to be susceptible to governance with the objective of achieving their effective mitigation, and have become the responsibility of the institutions and stakeholders of relevant social communities. An array of international, national and local laws dictate governance infrastructures, the roles of duty holders and beneficiaries and the relationships between them (the stakeholders), duties and rights (the stakes) and acceptable standards of safety and wellbeing (the ultimate rewards). Many regional, national and local stakeholders (individuals and entities) have a range of different, yet complementary, roles, duties, rights and powers. Much of this chapter, which has two main sections, represents a summary of a longer paper (Bretton et al. 2015) that addresses legal aspects of the future governance of volcanic risks. After a general introduction to relevant terminology in the first section, the second section describes the significant threat posed by periods of volcanic unrest.
\end{abstract}

R. J. Bretton $(\bowtie) \cdot$ J. Gottsmann

School of Earth Sciences, University of Bristol,

Wills Memorial Building, Queens Road, BS8 1RJ

Bristol, UK

R. J. Bretton · J. Gottsmann · R. Christie

The Cabot Institute, University of Bristol, Wills

Memorial Building, Queens Road, BS8 1RJ Bristol,

UK

R. Christie

School of Sociology, Politics and International

Studies, University of Bristol, 4 Priory Road, BS8

1TU Bristol, UK

Advs in Volcanology (2019) 23-34

DOI 10.1007/11157_2017_29

(C) The Author(s) 2017

Published Online: 28 November 2017 
The third section contains a general introduction to the critical concept of risk which lies at the heart of governance and provides a more detailed description of the many roles that national laws play. Reference is also made to international law which has an increasingly important role in the absence of relevant national laws, or when national laws are inadequate, ineffective or unenforced.

\section{Keywords}

Hazard · Risk · Risk governance $\cdot$ Legal duties

\section{Introduction}

This chapter describes the ways in which laws create the administrative and functional infrastructures that facilitate the effective mitigation of volcanic risks.

For the sake of brevity and clarity, we draw upon the existing rich discourse on relevant terminology (e.g. Fournier d'Albe 1979; Luhmann 1998, 1992; Power 2007, 2009; UN/ISDR 2009; Smith and Petley 2009; MIAVITA 2012) and adopt a number of brief working definitions.

A 'hazard' is an event (defined by risk-related temporal, spatial and other parameters) that may cause adverse effects. It is a complex function being the "probability of any particular area being affected by a destructive volcanic manifestation within a given period of time" (Fournier d'Albe 1979, 321). A 'volcanic hazard' is a volcanic scenario (defined by risk-related temporal, spatial and physical parameters) that may cause adverse consequences to people and/or valued assets.

In the early 1970 s, definitions of risk identified the product of three separate and distinct elements - 'vulnerability' on 'exposure' to a defined 'hazard' (UNESCO 1972). Bankoff et al. (2004) refers to volcanic hazards being one of three variables (hazard, exposure and vulnerability) that are convolved to produce volcanic risks. For the purposes of governance, it may be helpful to quantify each identified exposure in units of both number (i.e. the number of people exposed) and time (given that, by way of example, non-resident workers may be less exposed than full-time residents and 'vulnerability' may be related to length of exposure). ${ }^{1}$

'Governance' is a complex concept attracting a multitude of definitions (Walker et al. 2010). Although it "encompasses an array of organisations, practices and ideas" (Rothstein et al. 2012) that change over time, for sake of clarity, we embrace following definition.

\begin{abstract}
Governance is the sum of the many ways individuals and institutions, public and private, manage their common affairs. It is a continuing process through which conflicting or diverse interests may be accommodated and co-operative action may be taken. It includes formal institutions and regimes empowered to enforce compliance, as well as informal arrangements that people and institutions either have agreed to or perceive to be in their interest (Commission on Global Governance 1995, 4).
\end{abstract}

'Risk governance' includes all attempts to manage the three constituent variables of risk including steps to mitigate volcanic hazards (there are very few successful examples of this), reduce the exposure of people, assets etc. and reduce their vulnerability when exposed. This expression is adopted not only as an analytic term to describe stakeholders undertaking mitigation activities but also for 'normative' (i.e. evaluative standard) purposes. Risk governance

\footnotetext{
${ }^{1}$ The 18th report of the Scientific Advisory Committee on Montserrat Volcanic Activity contains a good example of a risk assessment which adopts this approach. It differentiates between the risks faced by residents in Zone A and those of workers involved in the shipment of sand from Plymouth Jetty.
} 
has a set of definable 'good' qualities that provide for the effective integration of the key components of how risks are handled by risk stakeholders (Walker et al. 2010; IRGC 2009).

\section{Geological Background}

Active volcanism can involve complex multi-hazard phenomena. Precursory unrest provides, by means of its signals, the monitoring data upon which evidence-based short-term hazard analysis is grounded. However, periods of mild unrest, even if they may not lead to an eruption, can themselves present a range of hazards including earthquakes, ground deformation, hydrothermal changes/eruptions and gas/ water chemistry changes. These precursory hazards can create societal risks that can escalate unnecessarily and therefore require very careful management. Unrest periods create, not only uncertainty about what is happening and resulting public alarm, anxiety and speculation, but also demands for information and advice (Johnston et al. 2002).

The evolution of an unrest period will depend upon its underlying causative processes, which can lead to different outcomes in different locations and with different spatial and physical properties (Rouwet et al. 2014; Sobradelo and Marti 2015).

Volcanic hazard communications and risk mitigation decisions rely upon the suitable and sufficient collection, and the correct analysis and interpretation of monitoring data, and the geological record (Newhall and Hoblitt 2002; Sparks et al. 2012; Rouwet et al. 2014). The analysis of monitoring data, which will often be limited in both quantity and quality, is challenging and there are many uncertainties in identifying causes and thereafter anticipating the evolution of unrest and imminent eruption (Sparks et al. 2012; Phillipson et al. 2013; Sobradelo and Marti 2015).

Hazard analysis is difficult and the risk governance stakes are high. Poorly handled unrest periods cause social, economic and political problems, even without an eruption. "Adverse response may take the form of the release of inappropriate advice, media speculation, unwarranted emergency declarations and premature cessation of economic activity and community services" (Johnston et al. 2002, 228).

\section{Risk Governance and Roles of Law}

The concept of risk as something that can be managed through human intervention is a relatively new one and important because it has become an increasingly pervasive concept in many societies. Risk is also associated with notions of choice, responsibility and blame (OECD 2015).

Risk evolved from its modest origins in the seventeenth century and became in the nineteenth century a principle for the objectification of possible experience - not only of the hazards of personal life and private venture, but also of the common venture of society (Gordon 1991).

By the late nineteenth century, risk had "become central to the rhetoric of regulation". State regulation of risk emerged as the means by which the state controlled economic activities in Western societies. The traditional objects of state regulation were manufactured risks, most particularly those resulting from scientific and technological innovation within manufacturing processes. The usual style of state regulation was "command and control" by imposing formal, structured and active risk management duties. The state exercised control through the promulgation of primary (i.e. enabling) and secondary (i.e. detailed implementing) laws and policing through specialist inspectorates.

In the twenty first century, regulation is no longer confined to non-natural, human-made risks. Many risks are, in whole or in part, recurring social manifestations (i.e. human-made phenomena) with negative consequences (Lauta 2014). In many cultures, particularly western cultures, they are no longer perceived as the consequences of external forces occurring independently of society and insusceptible to mitigation by society. Accordingly, they are now 
positioned within, and have become the responsibility of, the institutions and stakeholders of relevant social communities (Lauta 2014). These human-made risks are perceived to be susceptible to regulation with the objective of achieving their effective mitigation. By way of illustration, the population of Naples has greatly increased since 1944 and many would argue that the resulting increase in volcanic risk exposure is humanmade and capable of regulation.

Low probability-high impact risks pose a particular challenge for legislators. In fact there are three related challenges, namely scientific uncertainty, a low likelihood of occurrence, and significant societal consequences. Whilst the elevated consequences of these risks call for some level of regulation, the intrinsic uncertainty and low probability of their occurrence make it difficult to review the evidentiary scientific justification, to assess costs and benefits, and to identify means by which chosen regulatory goals can be pursued (Simoncini 2013).

In the absence of a tragedy, it is difficult to measure the performance of law-backed societal risk governance by the usual measures of: (1) economy (e.g. value for money) for input and process; (2) efficiency (e.g. quality delivered on time) for process and output; and (3) effectiveness for output and outcome. The indicators of outcome (the intended and unintended results) of the integrated governance system will be related to the impacts on, and the consequences for, public good, safety, security, health and welfare but it will be a challenge for any related targets (e.g. benchmarks and performance standards) to be SMART-Specific, Measurable, Achievable, Relevant and Timed (OECD 2002).

By contrast, in a fact-finding process of scrutiny after a tragedy, the use of SMART targets may become more practicable. It may be possible to measure hazard characterisation outputs against planned targets for timely delivery, user-friendliness, outcome-focussed, and temporal/spatial/intensity forecast accuracy. Based upon findings of fact, it may be feasible to quantify the resulting risk-mitigation impact measured in lives and assets saved.
Notwithstanding these challenges, many jurisdictions have national laws that attempt to regulate the management of risks arising from natural hazards. Many reflect the shift in paradigm, at both international and national levels, from focussing on ex-post, reactive response (the phases of emergency response and post-disaster longer term recovery) to ex-ante, pro-active risk management and mitigation (the phase of planning and preparedness) (UN SC-DRR 2009).

As illustrated in Fig. 1, national laws create governance infrastructures, duties of care and duty holders, rights and rights holders, enabling powers, regulators, enforcement powers, and lastly scrutiny venues. Each will now to considered in turn.

\subsection{The Creation of National Risk Governance Infrastructures}

National laws tend to identify, authorise and fund risk governance bodies (e.g. government departments and agencies, and public corporations) and public officials (e.g. individuals such governors, mayors, prefects and village heads) within a coherent legal and administrative framework, in other words, a risk governance infrastructure. These laws often use and build upon existing entities within existing administrative frameworks that have multi-level national, regional, district, municipal etc. political divisions and subdivisions.

In some jurisdictions, formal legal infrastructures anticipate and rely upon less formal structures and relationships at local levels nearer at-risk communities. For example, in Ecuador, the risk governance infrastructure relies upon the engagement and commitment of local representatives (e.g. chiefs and elders) and volunteers, such as hazard wardens/monitors, for both hazard data gathering and risk mitigation.

In some jurisdictions, such as Italy, the laws favour the imposition of duties upon individuals, rather than impersonal legal entities such as government departments/agencies and public companies. Legal duties may be founded upon an 


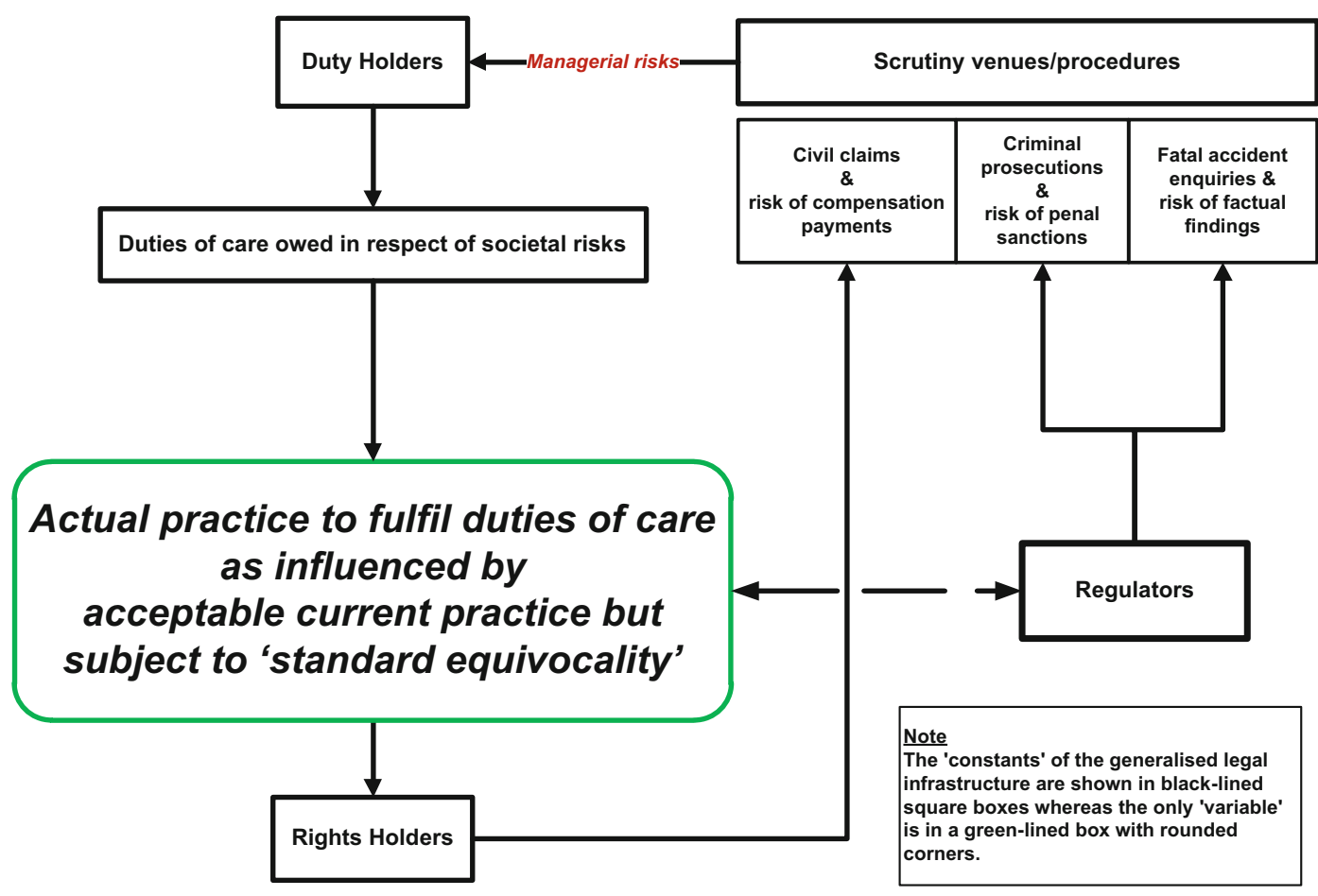

Fig. 1 The many roles of law in the governance of natural hazards set out in a generalised legal framework

individual having effective decision-making powers and control over financial resources rather than upon an individual holding a particular title or occupying a particular post (Bergman et al. 2007).

These infrastructures can be complex, confusing, fragmented and multi-level. They are often the creations of multiple sets of national primary (enabling) and secondary (detailed implementing) legislation supplemented as necessary by further provisions at ministerial, inter-ministerial, regional, provincial and local levels of government.

Occasionally additional specialised bodies are established (e.g. emergency management agencies, research/monitoring institutes and volcano observatories) with the creation of statutory roles to be filled by appointed individuals.

In a few known jurisdictions (e.g. USA, Canada and the Philippines) laws also regulate to varying degrees the qualification, licensing and registration of geologists and the practice of geology per se.

\subsection{The Creation of Duty and Rights}

National laws allocate to bodies and individuals (duty holders such as volcano observatories and civil protection authorities) high level management functions with responsibilities (duties of care), which are owed to the particular classes of people for whose benefit the duties were created (rights holders).

Since modest beginnings in the 1840's near Vesuvius Italy, the role of over 100 volcano observatories around the world has evolved. Observatories have at least two overlapping roles which involve a synergy of observation and theory. They have been described as 'critical in the volcanic risk reduction cycle" ${ }^{2}$ (Jolly 2015, 302), and employ and/or engage scientists who practice at the hazard-risk interface. The World Organisation of Volcano Observatories (WOVO), a Commission of the International

\footnotetext{
${ }^{2}$ This cycle includes periods before, during and after periods of volcanic unrest that may or may not lead to an eruption (Jolly 2015, 302).
} 
Table 1.1 Volcano observatories - three contrasting regimes

Montserrat-One individual with no powers of delegation

Section 8 of the Montserrat Volcano Observatory Act 2002 states that the Director of the Observatory shall be responsible for "reporting on the status of the volcanic activity in a regular and timely manner to the appropriate authorities" and "assisting in the dissemination to the public of information concerning the status of volcanic activity"

Alaska, USA —A group of institutions

"The Alaska Volcano observatory is a joint programme of the United States Geological Survey (USGS), the Geophysical Institute of the University of Alaska Fairbanks (UAFGI) and the State of Alaska Division of Geological and Geophysical Surveys (ADGGS)" (Jolly 2015, 299)

New Zealand-One institution under powers of delegation given to one individual

The Institute of Geological and Nuclear Sciences Limited (or GNS Science) is a Crown research institute created in 1992. The GNS has "sole responsibility for providing volcanic activity warnings and hence provides the function of a volcano observatory" (Jolly 2015, 299) under wide powers of delegation given to the Director of Civil Defence Emergency Management in the Civil Defence Emergency Management Act 2002

Association of Volcanology and Chemistry of the Earth's Interior (IAVCEI), is an organization of and for volcano observatories of the world. WOVO's website notes that its "members are institutions that are engaged in volcano surveillance and, in most cases, are responsible for warning authorities and the public about hazardous volcanic unrest".

Examples of three contrasting regimes are given in Table 1.1.

In some jurisdictions, general disaster management obligations are also imposed on 'the community' (i.e. members of the public) and non-government business entities. At-risk individuals and communities, businesses (such as aeroplane makers and operators within the aviation industry) and insurers have active and critical roles to play in the governance of volcanic risks, however, their roles are not the principal focus of either this chapter or Bretton et al. (2015). The needs and sentiments of all duty and rights holders, who depend upon and use geoscientific knowledge of volcanic hazards, must be identified and reflected carefully and clearly in the roles and interface practices of volcanologists.

During an emerging period of volcanic unrest, the relevant duty holders may change as the defined duties are transferred from one duty holder to another-sometimes as a result of changing hazard or risk characterisations. These duties of care can be framed in a wide variety of ways. They may relate to general health and safety, not specifying any risk creator (a particular hazard, natural or otherwise) or they may be more specific, identifying a particular hazard (ground uplift, earthquakes etc.).

Rights holders may be given the right to a safe and healthy environment, and to be represented, consulted or engaged in risk decisions and/or given information. Additional rights may be given to certain categories of persons due to special vulnerabilities and/or the influence of social structures and practices. These categories may include women, the very poor, older persons, children and people with disabilities (IFRC 2015).

There are two main types of duty of care, which are called here, respectively, 'functional' and 'goal-setting'. Functional duties dictate the fulfilment of a particular role (e.g. a duty to undertake monitoring, to prepare plans and programmes for emergency preparedness or to provide emergency preparedness communications and warnings). Goal-setting duties require the achievement of an outcome (e.g. a duty to ensure the safety and wellbeing of identified rights holders). Not even within the highly regulated field of occupational health are these safety goals absolute (i.e. unqualified). The imposition of an unrealistic absolute duty would give rights holders a theoretical guarantee of health and safety within a risk-free environment.

As a general rule, 'qualified' duties of care are therefore laid down. These duties represent 
democratic statements or mandates of 'acceptable' or 'optimal' risk after mitigation, and express a rational trade-off between safety and risk (Hood and Rothstein 2001; Rothstein 2014). Rothstein (2014) notes "After all, what is an acceptable risk other than a euphemistic boundary between an acceptable adverse outcome and an unacceptable failure".

Compliance with qualified duties inevitably requires duties holders to perform a risk-focussed cost/benefit analysis and a test of proportionality. A duty holder wishing to establish that societal risks have been reduced 'as low as reasonably practicable' has to show that the costs (the sacrifice) of further feasible safety measures would be grossly disproportionate to the additional safety benefits of those measures (based upon UK Office for Nuclear Regulation 2013).

Laws rarely, if ever, attempt to dictate, in either general or more detailed terms, the societal risk management arrangements that will be required to either fulfil a functional role or achieve a stated safety outcome. In practice, an assessment of societal vulnerability has two main stages. Firstly, the nature and scope of duties of care must be identified and delineated. This is essentially a matter of law and involves the legal interpretation of primary and secondary legislation and, if relevant, case law. Secondly, it is necessary to identify the actions that the duty holder should take to fulfil those duties. This is far more difficult. Competent lawyers can describe the safety function or outcome required in law-in football terms the dimensions and position of the goal. However, they can offer very limited guidance regarding the practical measures that the competent societal risk manager will need to take to achieve legal compliance (i.e. how to actually get the ball over the goal line).

In the case of food standards and occupational health and safety standards, it is common for national laws to set up government agencies to carry out research, to set performance standards and offer approved codes of practice or authoritative guidance. By contrast, in respect of volcanic hazards, at both the international and national levels, there appear to be neither:
(1) law-based performance standards offering guidance to societal risk managers; or (2) law endorsed self-regulatory regimes such as those that frequented the early stages of food regulation.

Within the 'goal-setting' legislative approach, referred to above, it is implicit that there is an obligation on duties holders to establish the nature and suitability (i.e. the legal adequacy) of their societal risk management arrangements. This difficult justification will usually be done post-facto, in other words, only after the risk outcome (perhaps a disaster properly so-called) is known and legal consequences are already being considered (Simoncini 2011). The justification will cover, but not be limited to, the arrangements that were necessary for the planning, organisation, control, monitoring and review of societal risk mitigation measures. To complete the authors' footballing analogy, post-facto legal processes are analogous to slow motion TV replays, in full view of partisan onlookers and experts with hindsight. They determine what has happened, whether or not a goal has been scored and, if not, why not and what effect any missed goal had on the final score (i.e. whether legal compliance has actually been achieved and, if not, why not and what the consequences should have been if compliance had been achieved).

'Standard equivocality', which is the absence of commonly recognised standards (norms), is likely to exist in the absence of clear 'legal' requirements, approved codes of practice or guidance. The resulting challenges faced by duty holders are: (1) to find or design authoritative standards or benchmarks to steer their societal risk management arrangements; and thereby (2) to increase their chances of fulfilling their societal risk duties of care and achieving legal compliance; and thereby (3) to minimise their vulnerability to managerial risks.

Rothstein (2002) and Hood (1986) have noted that, in the absence of commonly agreed and practical principles or methodologies by which compliance can be measured ('standardunequivocality'), process compliance is difficult to monitor and enforce. Other obstacles to monitoring, surveillance and enforcement include 
inherent scientific uncertainty, a dynamic state of scientific knowledge, a lack of expertise within regulatory agencies, and often complex and fragmented multi-level infrastructures. Donovan and Oppenheimer (2014) note complexities in governmental structures presented major challenges to managing volcanic eruptions in Montserrat. Recent crises including the 2010 Icelandic Eyjafjallajökull eruption have highlighted the difficulty of co-ordinating and synthesising scientific input from many different disciplines and institutions and translating these into useful policy advice at very short notice (OECD 2015).

\subsection{The Creation of Powers}

National laws have traditionally granted defined 'authorities' to government duty holders backed by administration, protection and intervention powers (ordinary, extraordinary and emergency). Governance, with an emphasis more on control than protection, has often been achieved by the exercise of authority using linear "coercion and enforcement" (Walker et al. 2010).

\subsection{The Creation of Regulators, Enforcement Powers and Scrutiny Venues}

Laws often establish, resource and empower regulators to monitor the performance of duty holders and to take enforcement actions, including prosecutions, against them if necessary. Examples of regulators include the Labour Standards Agency in Japan, the Department of Labour Health and Safety Service in New Zealand and the Occupational Safety and Health Agency in the United States of America. These regulators often have very wide powers similar to, and sometimes exceeding, those of police forces. They include the power to enter premises, to investigate and inspect, to acquire and preserve evidence and to serve notices.

Laws provide the formal scrutiny venues (courts, tribunals etc.) and related procedures for: (1) the ex-ante pro-active enforcement of duties of care by regulators, generally health and safety agencies; and (2) the ex-post facto reactive scrutiny of events, the identification of duty holders, the assessment of what happened and what should have happened and, if appropriate, the imposition of sanctions and/or the granting of remedies. The latter procedures are required at a national level to comply with the international law ex-post facto obligations which are now considered.

\subsection{The Role of International Law}

In the absence of relevant national laws, or when national laws are inadequate, ineffective or unenforced, there is room for the intervention of international law. The European Court of Human Rights (ECHR) has taken the lead and it is suggested here that in time the Inter-American Court of Human Rights will follow. The European Convention of Human Rights (EConHR) lays down a positive obligation on States to take appropriate steps to safeguard the lives of citizens within their jurisdiction. Article 2(1) EConHR provides that "Everyone's right to life shall be protected by law. No one shall be deprived of his life intentionally save in the execution of a sentence of a court following his conviction of a crime for which this penalty is provided by law."

In the context of the management of natural hazards, the most important case involving Article 2 arose in 2008. Budayeva and others v Russia (2008) ECHR 15339/02 concerned a mudslide. In this case, the EHCR considered principles that had been applied in Oneryildiz v Turkey (2004) to a human-made hazard - an industrial risk or dangerous activity such as the operation of a waste site. They were subsequently adopted in Kolyadenko and others $\mathrm{v}$ Russia (2012) in respect of natural flash floods.

\footnotetext{
Budayeva and others v Russia

The town of T was situated in a mountain district. Two tributaries passed through it and were known to have associated mudslides. A mud collector and a dam were constructed in order to protect $\mathrm{T}$. The dam was seriously damaged by a mud and debris
} 
flow in August 1999, so funds were requested to construct observation posts to warn of mudslides until it could be repaired, and to carry out certain emergency works to the dam.

Those measures were never implemented. A number of mudslides occurred in July 2000, killing eight residents, including the first applicant's husband, and destroying the applicants' homes. It was decided to dispense with a criminal investigation into the circumstances of the death of the first applicant's husband, and claims of compensation by the first applicant and others were refused on the basis that a mudslide of such exceptional force could neither have been predicted nor stopped. However, the applicants were granted substitute housing and a lump-sum emergency allowance.

The applicants complained to the ECHR, inter alia, that the authorities had violated the substantive limb of Article 2 of the EConHR. The first applicant asserted that the authorities were responsible for the death of her husband and she and the other applicants asserted that the authorities had failed to take appropriate measures to mitigate the risks to their lives posed by natural hazards.

The Court concluded that the relevant authorities were aware of the mudslides (the hazards) and their capacity to cause devastating consequences (the risks). There was no ambiguity about the scope and timing of the work that needed to be performed (the risk mitigation actions). After 1999, risk mitigation was not given proper consideration by the decision makers and budgetary bodies (the duty holders) and there was no functioning early warning system. State responsibility for the deaths had never been investigated. Each applicant was awarded compensation.

The EHCR determined that the obligation in Article 2 entails, above all, a primary duty on the State to put in place a clear legislative and administrative framework designed to provide effective deterrence against threats to the right to life. This applies in the context of any activity, whether public or not, in which the right to life may be at stake and extends not only to industrial risks and dangerous activities but also to actions and omissions to control natural hazards.

In the cases of Oneryildiz v Turkey (2004), Budayeva v Russia (2008), and Kolyadenko v Russia (2012), the EHCR determined that there is a positive obligation: (1) ex-ante to take substantive regulatory measures to manage risks; and (2) ex-post facto to ensure that any risk eventuated fatalities are followed by a public investigation. In relation to the latter, procedures must exist for identifying not only shortcomings in the ex-ante regulatory measures but also any errors committed by those responsible (i.e. duty holders). If there are any shortcomings and the infringement of the right to life was not intentional, it is not necessary for criminal proceedings to be brought in every case. It may satisfactory to make available to the victims civil law remedies (either alone or in conjunction with a criminal law remedy), enabling any responsibility of the parties concerned to be established and any appropriate civil redress, such as an order for the payment of damages, to be obtained.

The positive obligations of EConHR State duty holders under the ECHR are summarised in Fig. 2.

\subsection{The Role of International Institutions and Agencies}

In March 2015, the International Federation of Red Cross and Red Crescent Societies (IFRC) and the United Nations (UN) Development Programme issued the pilot version of "The checklist on law and disaster risk reduction". It encourages accountability mechanisms within legislation to address failures to fulfil risk governance responsibilities. In particular it advocates laws: (1) to establish public reporting or parliamentary oversight mechanisms and transparency requirements for government entities tasked with risk governance responsibilities; (2) to give a mandated role to the judiciary in enhancing accountability; (3) to provide enforceable incentives for compliance and disincentives for non-compliance; and (4) to establish legal and/or administrative sanctions (as appropriate) for public officials individuals and businesses for a gross ("particularly egregious") failure to fulfil their duties (IFRC 2015, 16).

The prioritisation of mitigation before response and recovery was recognised within the Sendai Framework for Disaster Risk Reduction 2015-2020 (the Sendai Framework) which 


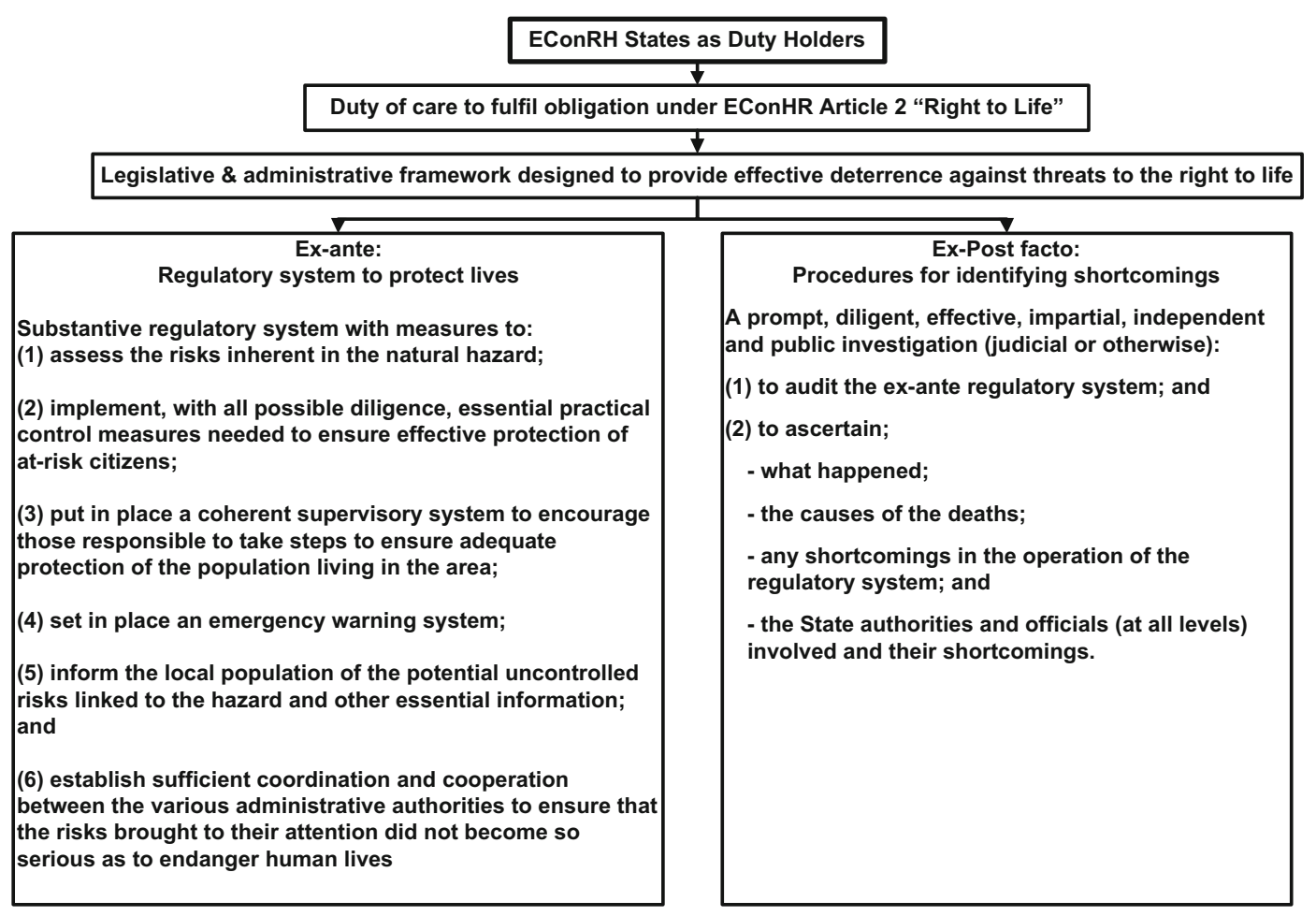

Fig. 2 The obligations of EConHR 'States' to manage natural hazards

emerged from the United Nations 3rd World Conference on Disaster Risk Reduction (UN/ISDR 2015). It is suggested here that one inevitable effect of the Sendai Framework will be to enhance the importance of not only the collection and interpretation of monitoring data but also the better characterisation of unrest periods. For the reasons stated in Sect. 2, periods of volcanic unrest, even if they do not lead to an eruption, present multiple hazards and risks which require very careful assessment and mitigation.

\section{Conclusions}

In many cultures, volcanic risks are perceived to be susceptible to governance and have become the responsibility of the institutions and stakeholders of relevant social communities.

Laws create the stakeholders, the stakes and the standards of risk governance. Without national laws, supplemented by international laws and initiatives, few countries would have the complex administrative infrastructures necessary for the mitigation of volcanic risks.

Although emergency response may still dominate thinking and funding in some jurisdictions, national laws are unlikely to diminish in number and/or reach in the light of the emerging international law governance norms, the IFRC/UN law checklist and the Sendai Framework.

\section{References}

Bankoff G, Frerks G, Hilhorst D (2004) Mapping vulnerability - disasters, development \& people. Earthscan, London and New York

Bergman D, Davis C, Rigby B (2007) International comparison of health and safety responsibilities of company directors, HSE research report RR 53, 207. http://www.hse.gov.uk/leadership/international.pdf 
Bretton RJ, Gottsmann J, Aspinall WP, Christie R (2015) Implications of legal scrutiny processes (including the L'Aquila trial and other recent court cases) for future volcanic risk governance. J Appl Volcanol 4:18. https://doi.org/10.1186/s13617-015-0034-x

Commission on Global Governance (1995) Our global neighbourhood. Oxford University Press, Oxford

Donovan A, Oppenheimer C (2014) Science, policy and place in volcanic disasters: insights from Montserrat. Environ Sci Policy 38:150-161 (May)

Fournier d'lbe EM (1979) Objectives of volcanic monitoring and prediction. J Geol Soc136:321-326. doi: https://doi.org/10:1144/gsjgs. 136.3.0321

Gordon C (1991) Governmental rationality: an introduction. In Burchell G, Gordon C, Miller P (eds) The foucault effect: studies in Governmentality. Harvester Wheatsheaf, Hemel Hempstead, pp 1-52

Hood C (1986) Administrative analysis: an introduction to rules, enforcement and organisations. Wheatsheaf Books, Sussex

Hood C, Rothstein H (2001) Risk regulation under pressure: problem solving or blame shifting? Adm Soc 33(1):21-53

International Federation of Red Cross, Red Crescent Societies (IFRC) and United Nations Development Programme (2015) The checklist on law and disaster risk reduction, Pilot version, March 2015. IFRC, Geneva, Switzerland. http://www.ifrc.org/PageFiles/ 115542/The-checklist-on-law-and-drr.pdf

International Risk Governance Council (IRGC) (2009) What is risk governance? www.irgc.org

Jolly G (2015) The role of volcano observatories in risk reduction. In: Loughlin SC, Sparks RSJ, Brown SK, Jenkins SF, Vye-Brown C (eds) Global volcanic hazards and risk. Cambridge University Press, Cambridge

Johnston D, Scott B, Houghton B, Paton D, Dowrick D, Villamor P, Savage J (2002) Social and economic consequences of historic caldera unrest at the Taupo volcano, New Zealand and the management of future episodes of unrest. Bull New Zealand Soc Earthquake Eng 35(4):215-229

Lauta KC (2014) Disaster law. Routledge, Oxford and New York

Luhmann N (1998) Observations on modernity. Stanford University Press, Stanford, CA

Luhmann N (1992) Risk: a sociology theory. de Gruyter, Berlin

MIAVITA (2012) Handbook for volcanic risk management: prevention, crisis management and resilience. MIAVITA team, Orleans

Newhall CG, Hoblitt RP (2002) Constructing event trees for volcanic crises. Bull Volcanol 64:3-20

OECD (Organisation for Economic Co-operation and Development) (2002) Outcome focussed management in the United Kingdom by Ellis K, Mitchell S. OECD Publications, Paris, France

OECD (2015) "Scientific advice for policy making: the role and responsibility of expert bodies and individual scientists", OECD science, technology and industry policy papers, no 21, OECD Publishing, Paris. http:// dx.doi.org/10.1787/5js3311jcpwb-en

Phillipson G, Sobradelo R, Gottsmann J (2013) Global volcanic unrest in the 21st century: an analysis of the first decade. J Volcanol Geoth Res 264(2013):183196

Power M (2007) Organised uncertainty: designing a world of risk management. Oxford University Press, Oxford

Power M (2009) The risk management of nothing. Acc, Organ Soc 34(2009):849-855

Rothstein H (2002) Neglected risk regulation: the institutional attenuation problem, centre for analysis of risk and regulation. London School of Economics and Political Science, London

Rothstein H (2014) Exploring national cultures of risk governance accessed via http://www.lse.ac.uk/ researchAndExpertise/units/CARR/publications/ CARRmagR\&R25-Rothstein.pdf

Rothstein H, Borraz O, Huber M (2012) Risk and the limits of governance: exploring varied patterns of risk-based governance across. Europe Regul Gov 121 http://doi.org/10.111/j.1748-5991.2012.01153.x

Rouwet D, Sandri L, Marzocchi W, Gottsmann J, Selva J, Tonini R, Papale P (2014) Recognizing and tracking volcanic hazards related to non-magmatic unrest: a review. J Appl Volcanol 3(1):17. https://doi.org/10. 1186/s13617-014-0017-3

Simoncini M (2011) Regulating catastrophic risks by standards. EJRR (1):37-50

Simoncini M (2013) Governing air traffic management in the single European sky: the search for possible solutions to safety issues. Eur Law Rev Issue 2 (2013):209-228

Smith K, Petley DN (2009) Environmental hazards: assessing risk and reducing disaster. Routledge, London and New York

Sobradelo R, Martí J (2015) Short-term volcanic hazard assessment through Bayesian inference: retrospective application to the Pinatubo 1991 volcanic unrest. J Volcanol Geoth Res 290(2015):1-11

Sparks RSJ, Aspinall WP, Auker M, Crosweller S, Hincks T, Mahony S, Nadim F, Polley J, Syre E (2012) Mapping and characterising volcanic risk, magmatic rifting and active volcanism conference, Addis Ababa, 12 Jan 2012

United Kingdom Office for Nuclear Regulation (2013) Guidance for the demonstration of ALARP (As Low As Reasonably Practicable) NS-TAST-GD-005 Revision 6

United Nations Educational, Scientific and Cultural Organization (UNESCO) (1972) Report of consultative meeting of experts on the statistical study of natural hazards and their consequences Document SC/WS/500 11pp, Paris, France

United Nations Development Programme Safer Communities through Disaster Risk Reduction in Development Programme SC-DRR (2009) Lessons learned: disaster management legal reform-The Indonesian experience UND-, Jakarta, Indonesia 
UN/ISDR (2009) Terminology on disaster risk reduction. Switzerland, Geneva

UN/ISDR (2015) Sendai framework for disaster risk reduction 2015-30

\section{Legal Authorities and Case Law}

Budayeva, others v Russia (2008) Applications 15339/02, $21166 / 02,20058 / 02,11673 \& 15343 / 02$, judgment of 20 March 2008, ECHR 15339/02

Open Access This chapter is licensed under the terms of the Creative Commons Attribution 4.0 International License (http://creativecommons.org/licenses/by/4.0/), which permits use, sharing, adaptation, distribution and reproduction in any medium or format, as long as you give appropriate credit to the original author(s) and the source, provide a link to the Creative Commons license and indicate if changes were made.
Walker G, Whittle R, Medd W, Watson N (2010) Risk governance and natural hazards, Cap Haz-Net WP2 Report, Lancaster Environment Centre, Lancaster University, Lancaster. http://caphaz-net.org/outcomessresults

Kolyadenko, others V Russia (2012) Applications 17423/05, 20534/05, 20678/05, 23263/05, 24283/05, 35673/05, ECHR 17423/05

Oneryildiz v Turkey (2004) Application 48939/99 18 BHRC 145, 41 EHRR 20
The images or other third party material in this chapter are included in the chapter's Creative Commons license, unless indicated otherwise in a credit line to the material. If material is not included in the chapter's Creative Commons license and your intended use is not permitted by statutory regulation or exceeds the permitted use, you will need to obtain permission directly from the copyright holder. 